\title{
Synthesis and characterization of cross-conjugated oligo(phenylene enynylene)s
}

\author{
Joon Cho, Yuming Zhao, and Rik R. Tykwinski* \\ Department of Chemistry, University of Alberta, Edmonton, AB, Canada T6G 2G2 \\ E-mail: rik.tykwinski@ualberta.ca
}

\section{Dedicated to Professor N. S. Zefirov on the occasion of his $70^{\text {th }}$ birthday}

(received 17 Feb 05; accepted 22 Apr 05; published on the web 12 May 05)

\begin{abstract}
The synthesis and characterization of a series of cross-conjugated oligo(phenylene enynylene)s via the Sonogashira protocol is reported. The structural properties of these oligomers have been established by ${ }^{1} \mathrm{H}$ and ${ }^{13} \mathrm{C}$ NMR and IR spectroscopies, as well as mass spectrometry. Their electronic absorption and emission behavior has been investigated via UV/Vis and fluorescence spectroscopy. The results of this study demonstrate that electronic communication along the conjugated framework of these oligomers is limited due to the presence of a cross-conjugated enyne framework and arylene fragments.
\end{abstract}

Keywords: Cross-conjugation, conjugated oligomer, Sonogashira coupling, enyne, blue emission

\section{Introduction}

The preparation of conjugated molecules of defined length and constitution is vital for the realization of both molecules and polymers suitable for use as materials for molecular-scale electronics, organic luminescent devices, and nonlinear optical (NLO) media. ${ }^{1}$ The ability to tailor organic molecular structure using organic synthetic techniques provides great versatility to modulate the properties of these molecules toward various applications. The study of conjugated organic oligomers with specific $\pi$-delocalization patterns can also provide the basis for the realization of useful polymer-based materials by using trends in the molecular properties to model those of the polymer system.

Many linearly conjugated oligomers have been explored as advanced materials, including those based on a framework of poly(phenylene ethynylene), ${ }^{2}$ polydiacetylene, ${ }^{3}$ and polytriacetylene. ${ }^{4}$ An alternative conjugation motif, namely cross conjugation, is also of interest in constructing oligomeric systems. Study on cross-conjugated iso-polydiacetylenes (iso-PDAs) ${ }^{5}$ 
and iso-polytriacetylenes (iso-PTAs) ${ }^{6}$ has shown that $\pi$-electron communication along the oligomer framework is moderated in comparison to linearly conjugated analogues, helping to maintain transparency in the visible region of their absorption spectra. These investigations have now been extended via the synthesis of hybrid oligomers that result from the insertion of an arylene spacer into the iso-PTA structure, namely the poly(phenylene enynylene)s. These oligomers can be viewed as isomeric derivatives of the linearly conjugated poly(phenylene ethynylene) and poly(phenylene vinylene), both of which are important semi-conducting organic polymers.

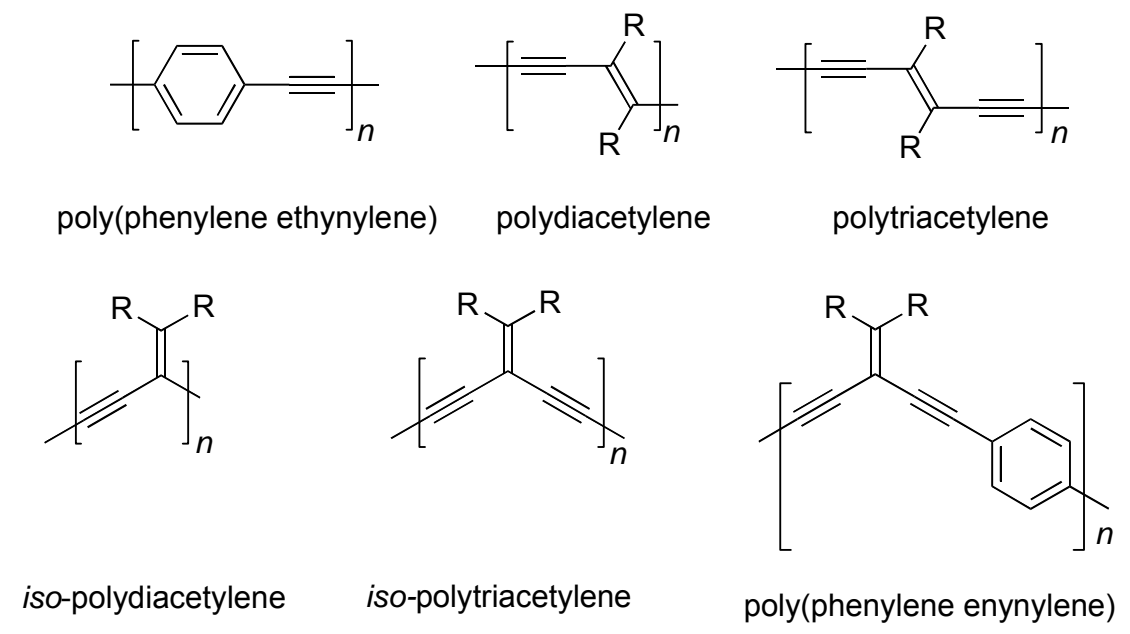

Figure 1. Linear and cross-conjugated oligomers.

In the present study, phenylene enynylene oligomers with precise length and defined structure have been assembled in an iterative manner using the palladium catalyzed Sonogashira coupling reaction. The structural properties of these new oligomers have been established by spectroscopic techniques, and their electronic absorption and emission characteristics have been evaluated. This study ultimately demonstrates that $\pi$-electron delocalization takes place only within each linearly conjugated segment, and little, if any, $\pi$-electron communication can be detected across the cross-conjugated backbone on the basis of these analyses.

\section{Results and Discussion}

An iterative divergent synthetic approach was employed to provide the cross-conjugated oligo(phenylene enynylene)s. To construct this series of oligomers, vinyl triflate 1 was targeted as a necessary structural building block (Scheme 1). A requisite precursor to $\mathbf{1}$, diyne 2a, is readily synthesized from commercially available 1-bromo-4-iodobenzene. ${ }^{7}$ Generally, FriedelCrafts acylation would be appropriate for the synthesis of ketone 3. ${ }^{8,9}$ In this case, however, attempted acylation of $\mathbf{2 a}$ via reaction with iso-butyryl chloride in the presence of $\mathrm{AlCl}_{3}$ resulted 
in numerous by-products, even at low temperature. To circumvent this problem, an alternative route was explored. Deprotection of 2a via selective removal of the trimethylsilyl group gave diyne $\mathbf{2 b}$. From compound $\mathbf{2 b}$, ketone $\mathbf{3}$ can be obtained via the reaction with iso-butyryl chloride under $\mathrm{CuI}$ catalysis and in the presence of triethylamine. ${ }^{10}$ This reaction gave 3 as a yellow oil in $96 \%$ yield. Ketone 3 can be efficiently converted into vinyl triflate 1 using a procedure adapted from that described by Stang et al. ${ }^{11}$ Thus, reaction of $\mathbf{3}$ with triflic anhydride in the presence of a sterically hindered pyridine base gave 1 as an orange oil in $85 \%$ yield following purification by column chromatography.

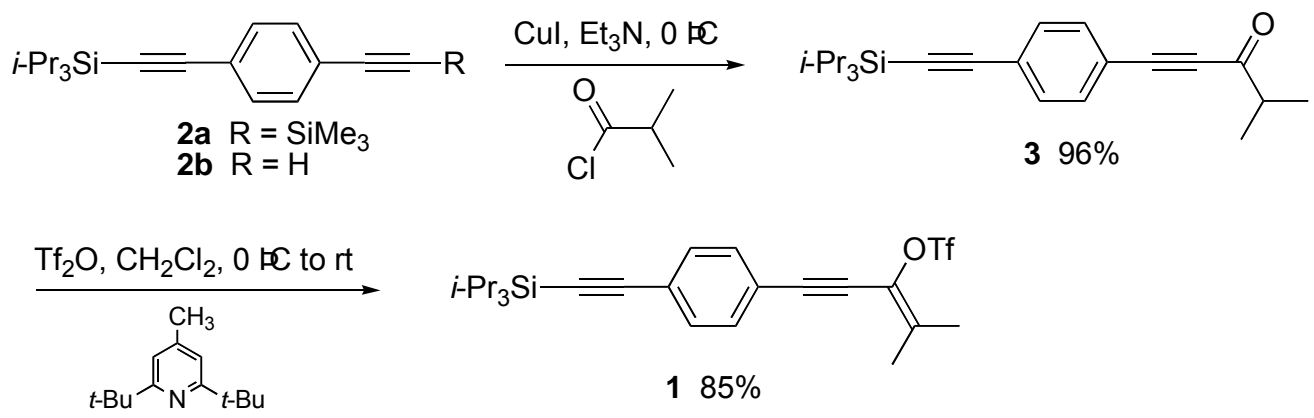

Scheme 1. Formation of vinyl triflate 1.

Using triflate 1, monomer 4, dimer 5, and trimer 6 can be generated as shown in Scheme 2 . Cross-coupling of terminal alkyne $\mathbf{2 b}$ with triflate $\mathbf{1}$ using typical Sonogashira coupling conditions, ${ }^{12} \mathrm{PdCl}_{2}\left(\mathrm{PPh}_{3}\right)_{2}$ as a catalyst, $\mathrm{CuI}$ as a co-catalyst, and diisopropylamine as base, gave an excellent yield of monomer 4 following column chromatography (silica gel). The analogous cross-coupling of triflate 1 with 1,4-diethynylbenzene gave dimer 5 in 38\% yield as an orange solid. The formation of trimer $\mathbf{6}$ first required the exhaustive deprotection of monomer $\mathbf{4}$ to afford the terminal alkyne precursor 7. This desilylation was done with tetrabutylammonium fluoride (TBAF) in a dilute THF solution. Unfortunately, the yield of this reaction was consistently low, with numerous by-products observed from TLC analysis during the reaction. Attempts to optimize the process by varying temperature showed that the best yields were obtained at a temperature around $-10{ }^{\circ} \mathrm{C}$. Since the deprotected compound 7 was not sufficiently stable for long-term storage, it was converted directly into trimer $\mathbf{6}$ following a brief reaction workup. The subsequent reaction of $\mathbf{7}$ with triflate $\mathbf{1}$ then gave trimer $\mathbf{6}$. Somewhat surprisingly, kinetic stability of these oligomers rapidly became an issue as a function of increasing oligomer length, and already at the stage of the trimer $\mathbf{6}$, instability caused difficulty in both separation and purification of the product. Nonetheless, trimer 6 can be isolated pure as an orange solid in $9 \%$ yield over the two steps from 4. All attempts toward the desilylation of dimer $\mathbf{5}$ and trimer $\mathbf{6}$ with TBAF toward the formation of longer oligomers, however, have led only to unidentified products of decomposition, irrespective of the conditions used. Thus, trimer 6 remains the longest derivative successfully constructed to date. 


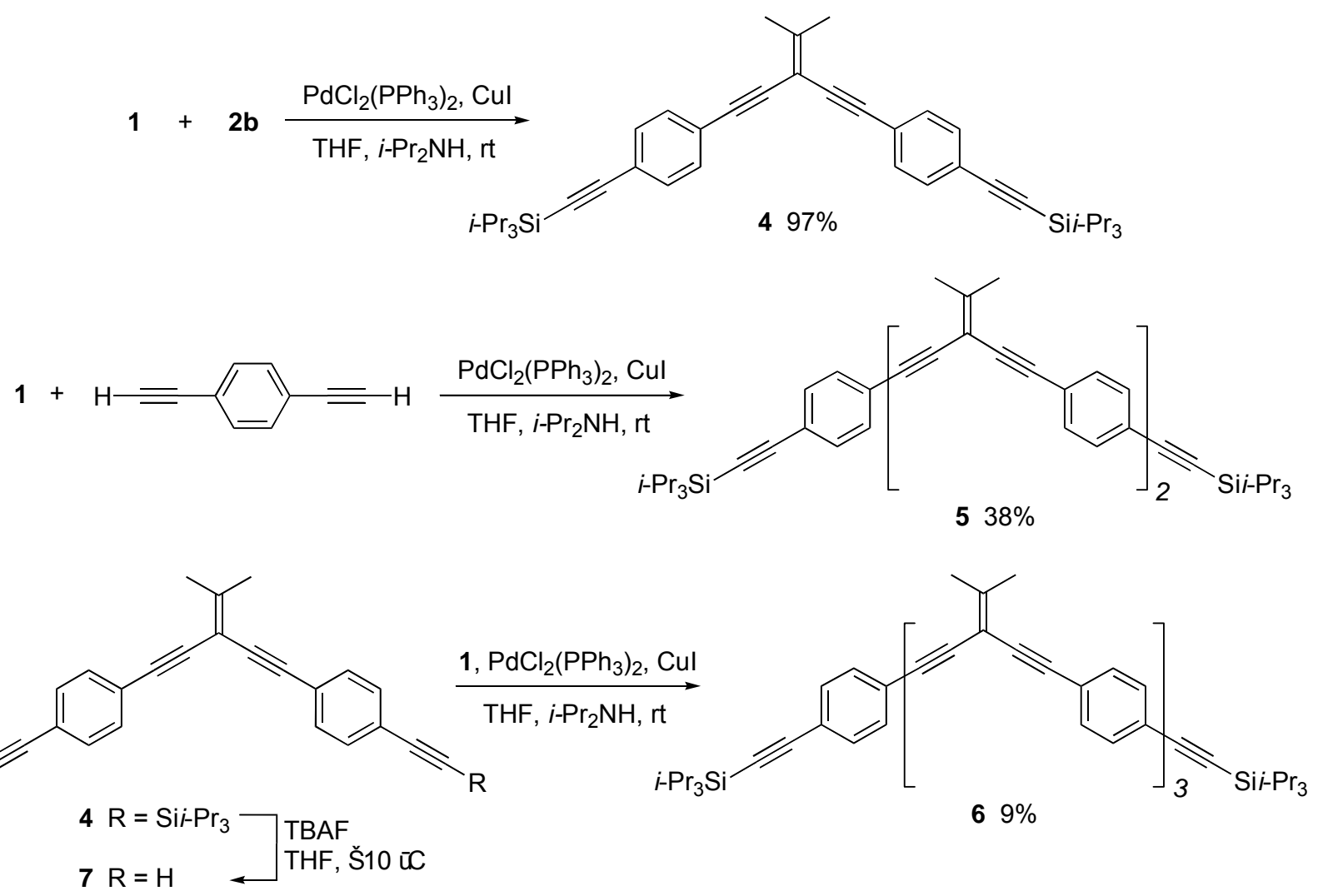

Scheme 2. Formation monomer 4, dimer 5, and trimer 6.

The iterative synthetic approach allows an investigation of cross-conjugated oligomers with precise length and defined structure, and comparisons of spectroscopic properties as a function of length are therefore possible. The ${ }^{1} \mathrm{H}$ NMR spectra of 4-6 are consistent with their proposed structures, and the most diagnostic feature in each case is the presence of broad singlets arising from the aryl protons. The ${ }^{13} \mathrm{C}$ NMR spectrum of monomer 4 shows a signal of the dimethyl alkylidene carbon $\left(\mathrm{C}=\mathrm{CMe}_{2}\right)$ shifted rather dramatically downfield to $155.5 \mathrm{ppm}$, and the other vinyl carbon $\left(C=\mathrm{CMe}_{2}\right)$ shifted upfield to $101.3 \mathrm{ppm}$, consistent with that observed for similar cross-conjugated molecules based on an isopropylidene framework. ${ }^{13}$ The four resonances of the sp-hybridized carbons are observed at 106.8, 92.7, 91.1, and $88.1 \mathrm{ppm}$, and that of the isopropylidene methyl groups is found at $23.0 \mathrm{ppm}$. The ${ }^{13} \mathrm{C}$ NMR spectrum of dimer 5 is similar, with signals of the vinyl carbons at 155.3 and $101.3 \mathrm{ppm}$, and five of the six expected resonances of the sp-hybridized carbons are found in the normal range. In the ${ }^{13} \mathrm{C} N M R$ spectrum of trimer 6, both unique vinylidene carbons $\left(\mathrm{C}=\mathrm{CMe}_{2}\right)$ are observed, at 155.25 and $155.20 \mathrm{ppm}$, while seven of the eight signals for the acetylenic carbons are visible. 


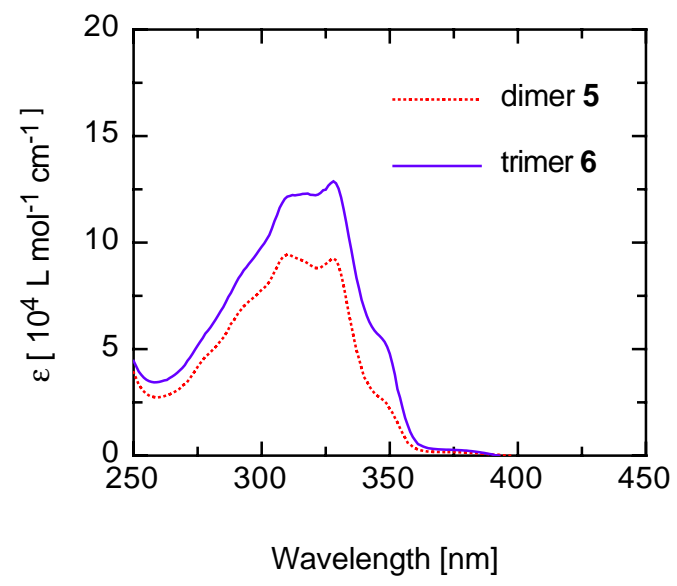

Figure 2. UV/Vis absorption spectra for dimer 5 and trimer $\mathbf{6}$ in $\mathrm{CHCl}_{3}$.

UV/Vis spectroscopic analysis of dimer $\mathbf{5}$ and trimer $\mathbf{6}$ was performed to investigate their electronic absorption behavior (Figure 2). These spectra show that both dimer 5 and trimer $\mathbf{6}$ possess similar absorption bands at 310 and $328 \mathrm{~nm}$, and a shoulder absorption at ca. $350 \mathrm{~nm}$. A broad, much less intense absorption $(\varepsilon<1000)$ from $360-390 \mathrm{~nm}$ is also observed. ${ }^{14}$ The similar UV/Vis characteristics for dimer 5 and trimer $\mathbf{6}$ suggest that there is little $\pi$-electronic communication via the framework of the oligomers as the chain length increases, even at the stage of the trimer. This outcome can be attributed to both cross conjugation and the phenylene spacer unit, which both diminish the $\pi$-delocalization along the oligomer backbone. As a result, the only major difference between the spectra of $\mathbf{5}$ and $\mathbf{6}$ is the accumulated effect in molar absorptivity $(\varepsilon)$ that takes place as a result of the additional number of repeat units for the trimer 6. This contrasts the behavior observed for cross-conjugated iso-PDAs, where a slight red shift in the lowest energy absorption was observed for oligomers up to 7-9 repeat units in length. ${ }^{5}$

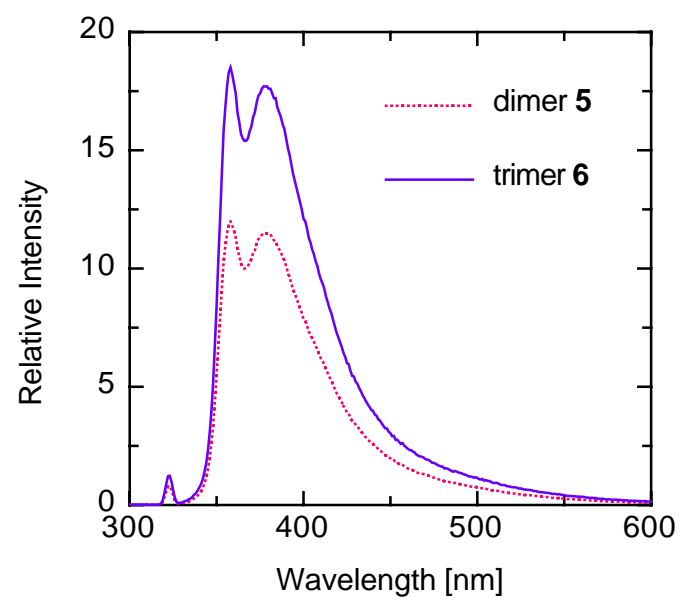

Figure 3. Emission spectra for dimer 5 and trimer $6 \mathrm{CHCl}_{3}$ (excitation at $326 \mathrm{~nm}$ ). 
Fluorescence spectra of dimer 5 and trimer $\mathbf{6}$ were obtained in dilute solutions of degassed chloroform and are shown in Figure 3. When irradiated at $326 \mathrm{~nm}$, both oligomers exhibit exactly the same blue emission bands at 359 and $381 \mathrm{~nm}$, and with the increasing oligomeric chain length, there is no apparent red shift in emission wavelength. Furthermore, upon varying the excitation wavelength from 250 to $347 \mathrm{~nm}$, both dimer 5 and trimer $\mathbf{6}$ gave the same emission maxima indicating that the emission is insensitive to the excitation wavelength. These results corroborate the observations from the electronic absorption analysis for $\mathbf{5}$ and $\mathbf{6}$, and confirms that the electronic properties of the oligomers are dominated by the longest linearly conjugated segment (shown in bold for trimer 6, Figure 4) and increased electronic communication is not obtained by increasing the oligomeric length.

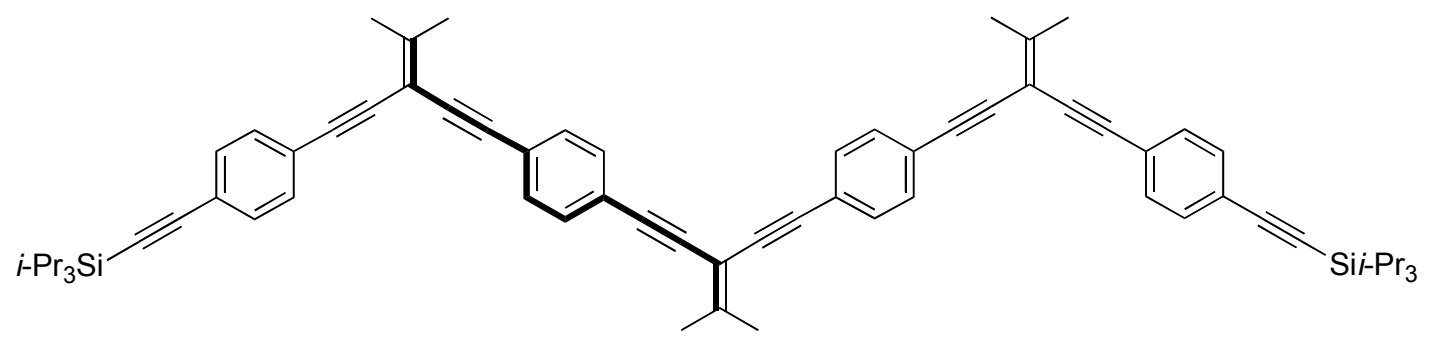

Figure 4. Schematic illustration of the longest linearly conjugated segment of trimer $\mathbf{6}$, shown in bold.

In conclusion, we have described the synthesis of the first members of a new class of crossconjugated organic oligomers. These compounds can be readily formed in a divergent manner using palladium catalyzed cross-coupling as a key synthetic step. Electronic absorption and emission spectroscopy suggests that electronic communication along the conjugated framework is severely limited due to cross conjugation, which results in similar absorption and emission wavelengths for oligomers regardless of length.

\section{Experimental Section}

General Procedures. Reagents and solvents were purchased reagent grade and used without further purification. Evaporation and concentration in vacuo was done at $\mathrm{H}_{2} \mathrm{O}$-aspirator pressure. All reactions were performed in standard glassware. A positive pressure of argon or nitrogen was essential to the success of all Pd-catalyzed reactions. Degassing of solvents was accomplished by vigorously bubbling argon or nitrogen through the solution for at least $30 \mathrm{~min}$. Column chromatography was done with Silica gel 60 (230-400 mesh) from Rose Scientific Ltd. using the solvent system described and thin-layer chromatography (TLC) used plastic sheets covered with silica gel 60 F254 from Macherey-Nagel and visualization by UV light or $\mathrm{KMnO}_{4}$ stain. UV/Vis spectroscopic measurements were done at room temperature using reagent grade $\mathrm{CHCl}_{3}$ at 
concentrations of ca. $5 \times 10^{-5} \mathrm{M}$. Emission measurements were done at room temperature using degassed reagent grade $\mathrm{CHCl}_{3}$ at concentrations of $<10^{-7} \mathrm{M}$.

Compound 1. To a solution of $3(0.74 \mathrm{~g}, 2.1 \mathrm{mmol})$ and 2,6-(di-tert-butyl)-4-methylpyridine $(0.53 \mathrm{~g}, 2.6 \mathrm{mmol})$ in $\mathrm{CH}_{2} \mathrm{Cl}_{2}(30 \mathrm{~mL})$ at $0{ }^{\circ} \mathrm{C}$ was added dropwise triflic anhydride $(0.90 \mathrm{~g}$, $3.2 \mathrm{mmol}$ ) under a nitrogen atmosphere. The reaction mixture was stirred at $\mathrm{rt}$ for $4 \mathrm{~h}$. The solvent was then removed, the residue was dissolved in pentane $(25 \mathrm{~mL})$, and the undissolved solid was removed by filtration. The pentane solution was washed with saturated aqueous $\mathrm{NH}_{4} \mathrm{Cl}$ and dried over $\mathrm{MgSO}_{4}$. After the solvent was removed, purification by column chromatography (silica gel, $\mathrm{CH}_{2} \mathrm{Cl}_{2} /$ hexanes $\left.1: 1\right)$ gave $1(0.87 \mathrm{~g}, 85 \%)$ as an orange oil. $R_{\mathrm{f}}=0.84$ $\left(\mathrm{CH}_{2} \mathrm{Cl}_{2} /\right.$ hexanes 1:1); IR (film): 2942, 2865, $2156 \mathrm{~cm}^{-1} ;{ }^{1} \mathrm{H}$ NMR $\left(300 \mathrm{MHz}, \mathrm{CDCl}_{3}\right): \delta 7.46$ $(\mathrm{AB} \mathrm{q}, J=8.4 \mathrm{~Hz}, 2 \mathrm{H}), 7.40(\mathrm{AB} \mathrm{q}, J=8.4 \mathrm{~Hz}, 2 \mathrm{H}), 2.07(\mathrm{~s}, 3 \mathrm{H}), 1.97(\mathrm{~s}, 3 \mathrm{H}), 1.14(\mathrm{~s}, 21 \mathrm{H})$; ${ }^{13} \mathrm{C}$ NMR $\left(75.5 \mathrm{MHz}, \mathrm{CDCl}_{3}, \mathrm{APT}\right): \delta 139.2,132.4,131.5,126.7,124.9,121.6,118.9(\mathrm{q}, J=$ $\left.320 \mathrm{~Hz}, \mathrm{CF}_{3}\right), 106.6,95.9,94.1,81.8,21.2,18.9,18.8,11.7$; EIMS m/z 484.2 (M $\left.\mathrm{M}^{+}, 18.8\right), 441.1$ ([M - i-Pr $\left.]^{+}, 100\right)$; HRMS (EI) calcd. for $\mathrm{C}_{24} \mathrm{H}_{31} \mathrm{~F}_{3} \mathrm{O}_{3} \mathrm{SSi}\left(\mathrm{M}^{+}\right) \mathrm{m} / \mathrm{z}$ 484.6536, found 484.1715.

Compound 3. To a solution of $\mathbf{2 b}(0.26 \mathrm{~g}, 0.93 \mathrm{mmol})$ and iso-butyryl chloride $(0.20 \mathrm{~g}$, $1.9 \mathrm{mmol})$ in triethylamine $(20 \mathrm{~mL})$ under a nitrogen atmosphere at $0{ }^{\circ} \mathrm{C}$ was added $\mathrm{CuI}(9.5 \mathrm{mg}$, $0.05 \mathrm{mmol}$ ). The reaction mixture was warmed and stirred at $\mathrm{rt}$ for $4 \mathrm{~h}$. The triethylamine was removed under reduced pressure. Methanol $(50 \mathrm{~mL})$ was added to quench the remaining isobutyryl chloride and the volatile components were removed under reduced pressure. The residue was extracted by diethyl ether $(2 \times 25 \mathrm{~mL})$, the solution washed with water $(50 \mathrm{~mL})$, and dried over $\mathrm{MgSO}_{4}$. After the solvent was removed, purification by column chromatography (silica gel, $\mathrm{CH}_{2} \mathrm{Cl}_{2} /$ hexanes $\left.1: 1\right)$ gave $3(0.32 \mathrm{~g}, 96 \%)$ as an orange oil. $R_{\mathrm{f}}=0.55\left(\mathrm{CH}_{2} \mathrm{Cl}_{2} /\right.$ hexanes 1:1); IR (film): 2942, 2865, 2198, $1673 \mathrm{~cm}^{-1} ;{ }^{1} \mathrm{H}$ NMR $\left(300 \mathrm{MHz}, \mathrm{CDCl}_{3}\right): \delta 7.48(\mathrm{AB} \mathrm{q}, J=8.4 \mathrm{~Hz}$, 2H), 7.45 (AB q, $J=8.6 \mathrm{~Hz}, 2 \mathrm{H}), 2.74$ (sept, $J=6.9 \mathrm{~Hz}, 1 \mathrm{H}), 1.24$ (d, $J=6.9 \mathrm{~Hz}, 6 \mathrm{H}), 1.11$ (s, $21 \mathrm{H}) ;{ }^{13} \mathrm{C}$ NMR $\left(75.5 \mathrm{MHz}, \mathrm{CDCl}_{3}\right.$, APT): $\delta 191.9,132.8,132.1,125.9,119.8,106.1,94.7,90.8$, 88.2, 43.1, 18.6, 18.0, 11.3; EIMS m/z 352.2 ( $\left.\mathrm{M}^{+}, 8.6\right), 309.2$ ([M - i-Pr $\left.]^{+}, 100\right)$; HRMS (EI) calcd. for $\mathrm{C}_{23} \mathrm{H}_{32} \mathrm{OSi}\left(\mathrm{M}^{+}\right) \mathrm{m} / \mathrm{z}$ 352.2222, found 352.2226.

Monomer 4. Diisopropylamine $(0.39 \mathrm{~g}, 3.9 \mathrm{mmol})$ was added to a stirred solution of $\mathbf{1}(0.63 \mathrm{~g}$, $1.3 \mathrm{mmol}), 2 \mathbf{b}(0.37 \mathrm{~g}, 1.3 \mathrm{mmol}), \mathrm{CuI}(25 \mathrm{mg}, 0.13 \mathrm{mmol})$, and $\mathrm{PdCl}_{2}\left(\mathrm{PPh}_{3}\right)_{2}(49 \mathrm{mg}$, $0.07 \mathrm{mmol})$ in degassed THF $(30 \mathrm{~mL})$ under a nitrogen atmosphere. The mixture was stirred at $\mathrm{rt}$ for $4 \mathrm{~h}$ and then diluted with diethyl ether $(25 \mathrm{~mL})$. The resulting solution was washed with saturated aqueous $\mathrm{NH}_{4} \mathrm{Cl}$ solution and dried over $\mathrm{MgSO}_{4}$. The solvent was removed and purification by column chromatography (silica gel, $\mathrm{CH}_{2} \mathrm{Cl}_{2} /$ hexanes $1: 10$ ) gave $4(0.78 \mathrm{~g}, 97 \%$ ) as an orange oil. Crystallization from $\mathrm{CH}_{2} \mathrm{Cl}_{2} / \mathrm{MeOH}$ gave an orange solid. $\mathrm{Mp}=92-96{ }^{\circ} \mathrm{C} ; R_{\mathrm{f}}=$ $0.43\left(\mathrm{CH}_{2} \mathrm{Cl}_{2} /\right.$ hexanes 1:10); IR $\left(\mathrm{CDCl}_{3}\right.$ film): 2942, 2865, $2152 \mathrm{~cm}^{-1} ;{ }^{1} \mathrm{H} \mathrm{NMR}(300 \mathrm{MHz}$, $\mathrm{CDCl}_{3}$ ): $\delta 7.40$ (br s, 8H), $2.14(\mathrm{~s}, 6 \mathrm{H}), 1.11$ (s, 42H); $\left.{ }^{13} \mathrm{C} \mathrm{NMR} \mathrm{(126} \mathrm{MHz,} \mathrm{CDCl}_{3}\right): \delta 155.3$, 131.9, 131.3, 123.3, 123.2, 106.8, 101.3, 92.7, 91.1, 88.1, 23.0, 18.7, 11.4; HRMS (EI) calcd. for $\mathrm{C}_{42} \mathrm{H}_{56} \mathrm{Si}_{2}\left(\mathrm{M}^{+}\right) \mathrm{m} / \mathrm{z}$ 616.3920, found 616.3917. Anal. calcd. for $\mathrm{C}_{42} \mathrm{H}_{56} \mathrm{Si}_{2}: \mathrm{C}, 81.75 ; \mathrm{H}, 9.15$. found: $\mathrm{C}, 81.93 ; \mathrm{H}, 9.23$. 
Dimer 5. Diisopropylamine $(0.08 \mathrm{~g}, 0.84 \mathrm{mmol})$ was added to a stirred solution of $1(0.14 \mathrm{~g}$, $0.28 \mathrm{mmol})$, 1,4-diethynylbenzene (18 mg, $0.14 \mathrm{mmol})$, CuI (5.7 $\mathrm{mg}, 0.03 \mathrm{mmol}$ ) and $\mathrm{PdCl}_{2}\left(\mathrm{PPh}_{3}\right)_{2}(7.1 \mathrm{mg}, 0.01 \mathrm{mmol})$ in degassed THF $(30 \mathrm{~mL})$ under a nitrogen atmosphere. The mixture was stirred at $\mathrm{rt}$ for $2 \mathrm{~h}$ and then diluted with diethyl ether $(25 \mathrm{~mL})$. The resulting solution was washed with saturated aqueous $\mathrm{NH}_{4} \mathrm{Cl}$ and dried over $\mathrm{MgSO}_{4}$. After the solvent was removed, purification by column chromatography (silica gel, $\mathrm{CH}_{2} \mathrm{Cl}_{2} /$ hexanes 1:7) gave 5 (41.8 mg, 38\%) as an orange oil. Crystallization from $\mathrm{CH}_{2} \mathrm{Cl}_{2} / \mathrm{MeOH}$ gave an orange solid. $\mathrm{Mp}=$ 142-146 ${ }^{\circ} \mathrm{C} ; R_{\mathrm{f}}=0.60\left(\mathrm{CH}_{2} \mathrm{Cl}_{2} /\right.$ hexanes 1:3); UV/Vis $\left(\mathrm{CHCl}_{3}\right): 310$ (94400), 328 (92500), 350 (21800) nm; IR ( $\mathrm{CDCl}_{3}$, film): 2942, 2864, $2153 \mathrm{~cm}^{-1} ;{ }^{1} \mathrm{H}$ NMR $\left(300 \mathrm{MHz}, \mathrm{CDCl}_{3}\right): \delta 7.42$ (s, 4H), 7.40 (br s, 8H), $2.14(\mathrm{~s}, 12 \mathrm{H}), 1.11(\mathrm{~s}, 42 \mathrm{H}) ;{ }^{13} \mathrm{C} \mathrm{NMR}\left(75.5 \mathrm{MHz}, \mathrm{CDCl}_{3}, \mathrm{APT}\right): \delta 155.3$, $131.9,131.4,131.3,123.3,123.2,123.1,106.8,101.3,92.7,91.2,91.1,88.1,23.0,18.7,11.3$ (two coincident carbons not observed); EIMS m/z 751.4 ([M - i-Pr $]^{+}, 72.3$ ); HRMS (EI) calcd. for $\mathrm{C}_{53} \mathrm{H}_{59} \mathrm{Si}_{2}\left(\mathrm{M}^{+}\right) \mathrm{m} / \mathrm{z}$ 751.4155, found 751.4141 ([M - i-Pr $\left.]^{+}\right)$. ESI MS ( $\mathrm{CDCl}_{3}, \mathrm{AgOTf}$ added) calcd. for $\mathrm{C}_{56} \mathrm{H}_{66} \mathrm{AgSi}_{2}\left([\mathrm{M}+\mathrm{Ag}]^{+}\right) \mathrm{m} / \mathrm{z}$ 903.2, found 903.4.

Compound 7. To a solution of $4(0.20 \mathrm{~g}, 0.32 \mathrm{mmol})$ in wet $\mathrm{THF}(25 \mathrm{~mL})$ at $-10{ }^{\circ} \mathrm{C}$ was added dropwise a $1 \mathrm{M}$ solution of tetrabutylammonium fluoride in THF $(0.64 \mathrm{~mL}, 0.64 \mathrm{mmol})$. The solution was stirred for $30 \mathrm{~min}$ and then diluted with diethyl ether. After the solvent was removed, purification by column chromatography (silica gel, $\mathrm{CH}_{2} \mathrm{Cl}_{2} /$ hexanes 1:1) of the residue afforded $7(26 \mathrm{mg}, 27 \%)$ as an unstable orange oil that was carried on immediately to the formation of 6. $R_{\mathrm{f}}=0.68$ (hexanes); IR (film) 2927, 2865, $2152 \mathrm{~cm}^{-1}$; ${ }^{1} \mathrm{H} \mathrm{NMR} \mathrm{(300} \mathrm{MHz,}$ $\left.\mathrm{CDCl}_{3}\right): \delta 7.42(\mathrm{~s}, 8 \mathrm{H}), 3.14(\mathrm{~s}, 2 \mathrm{H}), 2.14(\mathrm{~s}, 6 \mathrm{H})$; EIMS m/z $304.1\left(\mathrm{M}^{+}, 100\right)$; HRMS (EI) calcd. for $\mathrm{C}_{24} \mathrm{H}_{16}\left(\mathrm{M}^{+}\right) \mathrm{m} / \mathrm{z} 304.1252$, found 304.1248.

Trimer 6. Diisopropylamine $(1.08 \mathrm{~mL}, 7.6 \mathrm{mmol})$ was added to a stirred solution of $1(0.12 \mathrm{~g}$, $0.24 \mathrm{mmol}), 7$ (74 mg, $0.12 \mathrm{mmol}), \mathrm{CuI}$ (19 $\mathrm{mg}, 0.01 \mathrm{mmol})$ and $\mathrm{PdCl}_{2}\left(\mathrm{PPh}_{3}\right)_{2}(70 \mathrm{mg}$, $0.01 \mathrm{mmol})$ in degassed THF $(30 \mathrm{~mL})$ under a nitrogen atmosphere. The solution was stirred at $\mathrm{rt}$ for $4 \mathrm{~h}$ and then diluted with diethyl ether $(25 \mathrm{~mL})$. The resulting solution was washed with saturated aqueous $\mathrm{NH}_{4} \mathrm{Cl}$ and dried over $\mathrm{MgSO}_{4}$. After the solvent was removed, column chromatography (silica gel, $\mathrm{CH}_{2} \mathrm{Cl}_{2} /$ hexanes 1:3) gave $6(11 \mathrm{mg}, 9 \%$ ) as an orange oil. Crystallization from $\mathrm{CH}_{2} \mathrm{Cl}_{2} / \mathrm{MeOH}$ gave an orange solid. $\mathrm{Mp}=127-128{ }^{\circ} \mathrm{C} ; R_{\mathrm{f}}=0.39$ $\left(\mathrm{CH}_{2} \mathrm{Cl}_{2} /\right.$ hexanes 1:3); UV/Vis $\left(\mathrm{CHCl}_{3}\right): 310$ (122000), 328 (129000), 350 (47800) nm; IR ( $\mathrm{CDCl}_{3}$ film): 2924, 2863, $2153 \mathrm{~cm}^{-1} ;{ }^{1} \mathrm{H} \mathrm{NMR} \mathrm{(300} \mathrm{MHz,} \mathrm{CDCl}_{3}$ ): $\delta 7.42$ (br s, 8H), 7.40 (br s, $8 \mathrm{H}), 2.14$ (br s, $18 \mathrm{H}), 1.11$ (s, 42H); $\left.{ }^{13} \mathrm{C} \mathrm{NMR} \mathrm{(126} \mathrm{MHz,} \mathrm{CDCl}_{3}, \mathrm{APT}\right): \delta 155.24,155.20$, $131.9,131.4,131.3,123.3,123.2,123.1,106.8,101.3,92.7,91.2,91.1,88.10,88.06,23.0,18.7$, 11.4 (seven coincident carbons not observed); ESI MS ( $\mathrm{CDCl}_{3}, \mathrm{AgOTf}$ added) calcd. for $\mathrm{C}_{70} \mathrm{H}_{76} \mathrm{AgSi}_{2}\left([\mathrm{M}+\mathrm{Ag}]^{+}\right) \mathrm{m} / \mathrm{z} 1081$, found 1081. While HRMS analysis was not possible, the calculated and experimental isotopic distributions for $[6+\mathrm{Ag}]^{+}(\mathrm{m} / \mathrm{z} 1081)$ were identical 


\section{Acknowledgements}

This work was supported by the Natural Sciences and Engineering Research Council of Canada (NSERC) and the University of Alberta.

\section{References and Notes}

1. (a) Lunström, I.; Salaneck, W. R.; Ranby, B. Eds Conjugated Polymers and Related Materials. The Interconnection of Chemical and Electronic Structure; Oxford University Press: Oxford, 1993. (b) Martin, R. E.; Diederich, F. Angew. Chem., Int. Ed. 1999, 38, 1350. (c) Müllen, K.; Wegner, G., Eds Electronic Materials: The Oligomer Approach; WileyVCH: Weinheim, 1998.

2. (a) Bunz, U. H. F. Chem. Rev. 2000, 100, 1605. (b) Meier, H.; Ickenroth, D.; Stalmach, U.; Koynov, K.; Bahtiar, A.; Bubeck, C. Eur. J. Org. Chem. 2001, 4431.

3. Sarkar, A.; Okada, S.; Matsuzawa, H.; Matsuda, H.; Nakanishi, H. J. Mat. Chem. 2000, 10, 819.

4. Martin, R. E.; Gubler, U.; Cornil, J.; Balakina, M.; Boudon, C.; Bosshard, C.; Gisselbrecht, J.-P.; Diederich, F.; Günter, P.; Gross, M.; Brédas, J.-L. Chem. Eur. J. 2000, 6, 3622.

5. (a) Zhao, Y.; Slepkov, A. D.; Akoto, C. O.; McDonald, R.; Hegmann, F. A.; Tykwinski, R. R. Chem. Eur. J. 2004, 11, 321. (b) Tykwinski, R. R.; Zhao, Y. Synlett 2002, 1939. (c) Slepkov, A. D.; Hegmann, F. A.; Zhao, Y.; Tykwinski, R. R.; Kamada, K. J. Chem. Phys. 2002, 116, 3834.

6. (a) Zhao, Y.; McDonald, R.; Tykwinski, R. R. J. Org. Chem. 2002, 67, 2805. (b) Burri, E.; Diederich, F.; Nielsen, M. B. Helv. Chim. Acta 2002, 85, 2169.

7. Godt, A.; Ünsal, Ö.; Roos, M. J. Org. Chem. 2000, 65, 2837.

8. Walton, D. R. M.; Waugh, F. J. Organomet. Chem. 1972, 37, 45.

9. Chowdhury, C.; Kundu, N. G. Tetrahedron Lett. 1996, 37, 7323.

10. Ramachandran, P. V.; Teodorovic, A. V.; Rangaishenvi, M. V.; Brown, H. C. J. Org. Chem. 1992, 57, 2379.

11. Stang, P.; Fisk, T. E. Synthesis 1979, 438.

12. (a) Sonogashira, K.; Tohda, Y.; Hagihara, N. Tetrahedron Lett. 1975, 4467. (b) Tykwinski, R. R. Angew. Chem. Int. Ed. 2003, 42, 1566.

13. Eisler, S.; McDonald, R.; Loppnow, G. R.; Tykwinski, R. R. J. Am. Chem. Soc. 2000, 122, 6917.

14. While it is possible that this absorption results from the presence of butadiynyl moieties by means of a oxidative acetylenic homo-coupling side reaction, no evidence of such an impurity could be found by NMR spectroscopic or TLC analysis of the purified sample. 